\title{
Synthesis of a Hexafluoropropylidene-Bis (phthalic anhydride)-Based Polyimide and Its Conducting Polymer Composites with Polypyrrole
}

\author{
FATMA SELAMPINAR, ${ }^{1}$ URAL AKBULUT, ${ }^{1}$ TULAY YILMAZ, $^{2}$ ATTILA GUNGOR, ${ }^{2}$ LEVENT TOPPARE $^{3}$ \\ ${ }^{1}$ Department of Chemistry, Middle East Technical University, 06531 Ankara, Turkey \\ ${ }^{2}$ Gebze Research Center of Turkish Scientific Research Council, Turkey \\ ${ }^{3}$ Department of Chemistry, Bilkent University, 06533 Ankara, Turkey
}

Received 23 December 1996; accepted 6 April 1997

\begin{abstract}
A new electrically conducting composite film from polypyrrole and 4,4'(hexafluoroisopropylidene)-bis (phthalic anhydride)-based polyimide was prepared. Pyrrole and the dopant ion can easily penetrate through the polyimide substrate and electropolymerize on the platinum $(\mathrm{Pt})$ electrode due to the swelling of the polyimide on the metal electrode. The electrochemical properties of polypyrrole-polyimide (PPy/ PI) composite films have been investigated by using cyclic voltammetry. The PPy/PI composite film is suitable for use as the electroactive material owing to its stable and controllable electrochemical properties. The electrical conductivity of composites falls in the range 0.0035-15 S/cm. Scanning electron micrograph, FTIR, and thermal studies indicate that PPy and PI form a homogeneous material rather than a simple mixture. (C) 1997 John Wiley \& Sons, Inc. J Polym Sci A: Polym Chem 35: 3009-3016, 1997
\end{abstract}

Keywords: conducting polymer; composite; polyimide; electroinitiation; polypyrrole

\section{INTRODUCTION}

A number of potential applications of conducting polymers are expected because they can be formed into thin, mechanically strong films, and it is obviously desirable to confer the additional property of electrical conductivity on polymers that already benefit from being flexible and compact. There has been a great deal of interest in the areas such as rechargeable batteries, ${ }^{1,2}$ gas separation membranes, ${ }^{3}$ shielding, ${ }^{4}$ and electrochromic display devices. ${ }^{5}$ Of these polymers, the electrochemically prepared polylpyrroles stand out as an excellent class of materials due to their high conductivity, relative environmental stability in the oxidized

\footnotetext{
Correspondence to: L. Toppare
}

Journal of Polymer Science: Part A: Polymer Chemistry, Vol. 35, 3009-3016 (1997) ๑ 1997 John Wiley \& Sons, Inc. CCC 0887-624X/97/143009-08 form, and ease of preparation. However, their poor mechanical properties and processability constitute major obstacles to their applications. Various ways such as introducing alkyl group into the main chain, the synthesis of soluble precursors, and the preparation of conducting polymer composites can be used to improve the mechanical properties. The most effective way is the preparation of composites. The electrochemical preparation of electrically conductive composites has led to the synthesis of materials with controllable electrical and mechanical properties. In recent years several composites of conducting polymers with insulating polymers have been prepared. In these systems, the electrochemical polymerization of a monomer within a predeposited, solvent swollen polymer matrix on an electrode surface was achieved. The insulating polymers that have been used include polyamide, ${ }^{6}$ polyvinyl chlo- 
ride,${ }^{7}$ poly (vinyl alcohol),${ }^{8}$ polypropylene,${ }^{9}$ and polycarbonate. $^{10}$

As a result of the increased need for advanced materials, extensive research studies have been done on thermally stable polymers usable up to $350^{\circ} \mathrm{C}$ for a prolonged time. Chemical structures which are thermally stable usually have a highly resonance-stabilized system, including an aromatic or other thermally unreactive ring structure, as the major portion of the polymer composition and high bond and cohesive energy densities. ${ }^{11}$ In view of these requirements, aromatic polyimides are one of the most promising classes of high-performance polymers. They have found applications as high-temperature insulators and dielectrics, coatings adhesives, and matrices for high-performance composites demanded by space and advanced aircraft industries. ${ }^{11-15}$

The syntheses of polyimides are mostly accomplished by the two-step method in which a tetracarboxylic acid dianhydride is reacted with a solution of diamine in a polar aprotic solvent at 15$25^{\circ} \mathrm{C}$ to form poly (amic acid) in the first stage. In the second step of the synthesis, poly (amic acid) is cyclodehydrated to the corresponding polyimide by either extended heating at an elevated temperature in bulk or in solution, ${ }^{11,12}$ by treating with chemical dehydrating agents, ${ }^{13,16}$ or by microwave energy ${ }^{17,18}$ Although the most common way is the bulk thermal imidization, in this technique it is necessary to raise the temperature above the glass transition temperature of the fully imidized material in order to provide adequate chain mobility to obtain high degree of imidization. However, this may often lead to undesired side reactions which decreases the solubility, fusability, and processability of the final product.

Since aromatic polyimides have been replacing metals in environmentally harsh applications that require prolonged high-temperature stability and resistance to moist and humid environments, these desirable properties may be combined with the electrical conductivity of polypyrrole.

In this work following the synthesis of 4,4'-bis (3aminophenoxy)diphenyl sulfone (DAPDS), ${ }^{19,20}$ by nucleophilic aromatic substitution of $4,4^{\prime}$-dichlorophenyl sulfone with $m$-aminophenol, DAPDS $/ 4,4^{\prime}$ (hexafluoropropylidene)-bis(phthalic anhydride) (6FDA) based soluble and processable fully imidized polyimides were successfully synthesized by using the solution imidization technique, instead of bulk imidization, without sacrificing their desirable properties. In addition, we report the preparation of a composite, PI/PPy, by the electrochemical polymerization of pyrrole on a PI-coated electrode. Electrolytic films were characterized by FTIR, SEM, TGA, DSC, and conductivity measurements.

\section{EXPERIMENTAL}

\section{Materials}

4,4'-(Hexafluoropropylidene)-bis (phthalic anhydride) (6FDA) was provided from Hoechst Celanese Corp. and was used as received. $N$-Methylpyrrolidinone (NMP) and $N, N$-dimethylacetamide (DMAc), used as the solvents, were purified by distillation over phosphorus pentoxide. $o$-Dichlorobenzene, the azeotroping agent, was obtained from Riedel de Haen and was used as received.

Pyrrole (Aldrich) was distilled before use. The tetrabutylammonium tetrafluoroborate (TBAFB) (Aldrich) was dried under vacuum at $100^{\circ} \mathrm{C}$ for 12 h. Acetonitrile (Merck) and $\mathrm{CHCl}_{3}$ (Merck) were used as received.

Monomer Synthesis: 4,4'-Bis (3aminophenoxy) diphenyl Sulfone (DAPDS) ${ }^{19,20}$

This was synthesized from dichlorophenyl sulfone (DCDPS) (50.0 g, $0.17 \mathrm{~mol}$ ), 3-aminophenol (37.1 $\mathrm{g}, 0.34 \mathrm{~mol})$, and anhydrous $\mathrm{K}_{2} \mathrm{CO}_{3}(51.1 \mathrm{~g}, 0.37$ mol) by nucleophilic aromatic substitution reaction using DMAc ( $210 \mathrm{~mL})$ as the aprotic dipolar solvent and $o$-dihlorobenzene $(50 \mathrm{~mL})$ as the azeotroping agent. The crude product was precipitated from water and was further purified by successive crystallization from ethanol. The pure product was characterized by ${ }^{13} \mathrm{C}-\mathrm{NMR}$, FTIR, and elemental analysis and potentiometric titration for amine determination $^{21}$ (yield 80\%; m.p. $131-133^{\circ} \mathrm{C}$; MW $=433.5 \mathrm{~g} /$ mol (by amine titration).
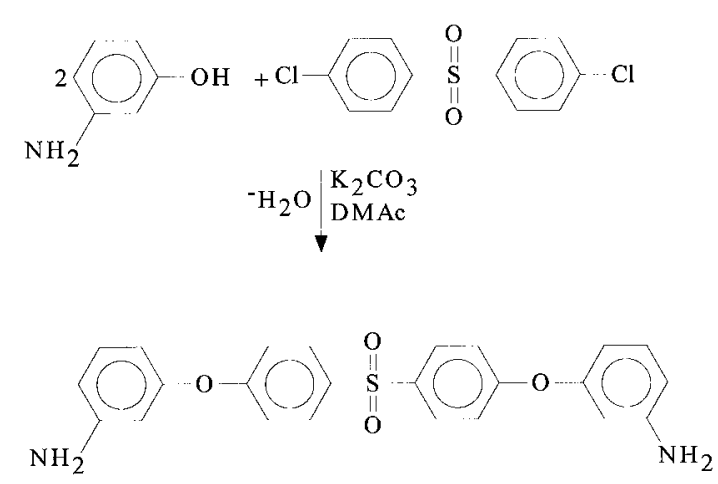

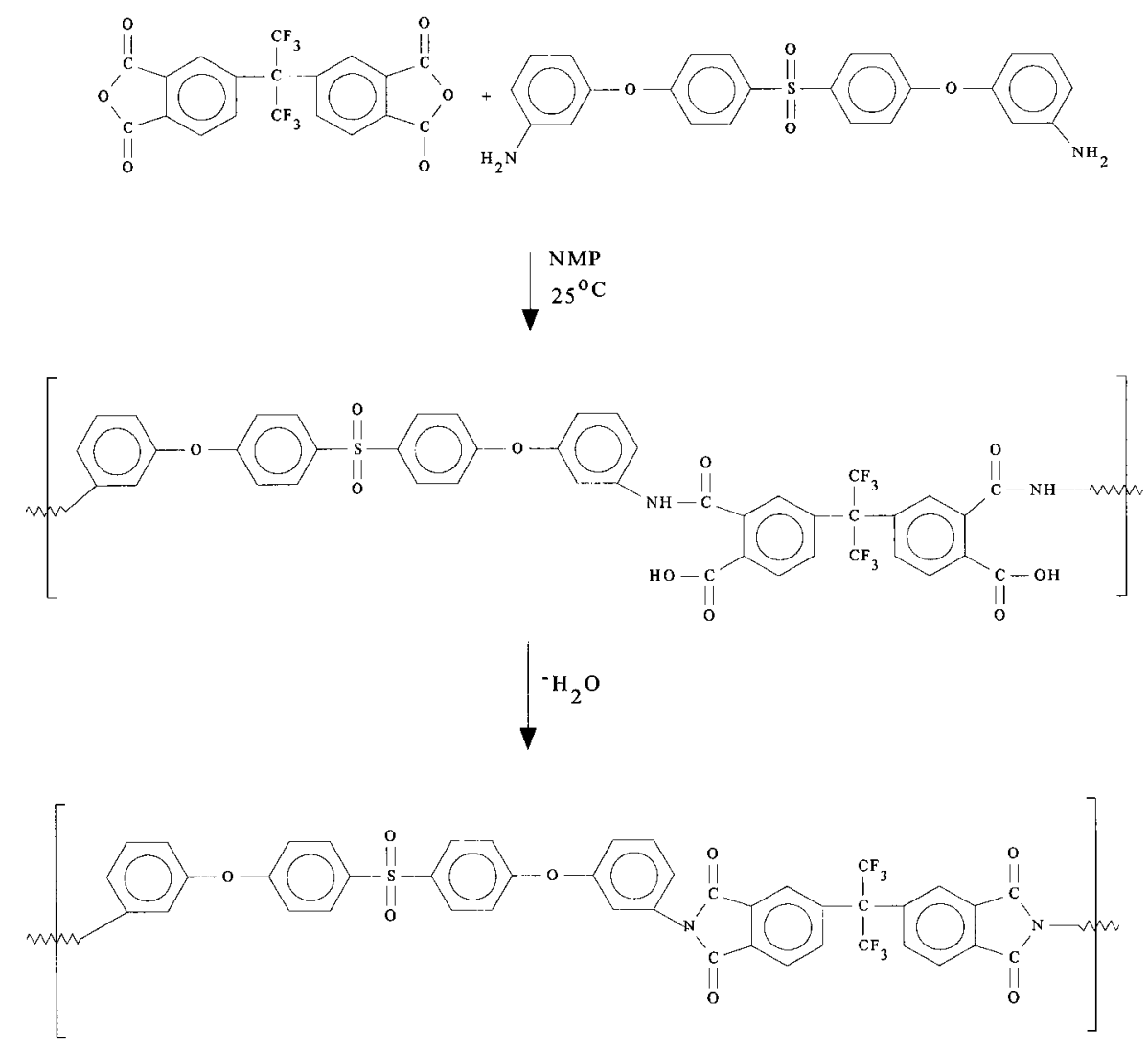

Scheme 1.

${ }^{13} \mathrm{C}-\mathrm{NMR}, \mathrm{APT}\left(\mathrm{DMSO}-d_{6}\right): \delta=161.8\left(\mathrm{SO}_{2}^{-} \mathrm{C}_{\mathrm{arom}, 4^{\circ}}\right.$, $2 \mathrm{C}) ; 155.9\left(\mathrm{O}-\mathrm{C}_{\text {arom }, 4^{\circ}}, 2 \mathrm{C}\right) ; 148.2\left(\mathrm{O}-\mathrm{C}_{\text {arom }, 4^{\circ}}\right.$, $2 \mathrm{C}$, meta to $\left.\mathrm{NH}_{2}\right) ; 135.4\left(\mathrm{C}_{\text {arom, } 4^{\circ}}-\mathrm{NH}_{2}, 2 \mathrm{C}\right) ; 130.5$ $\left(\mathrm{C}_{\text {arom }, 3^{\circ}}\right.$ ortho to $\mathrm{O}$ and $\left.\mathrm{NH}_{2}, 2 \mathrm{C}\right) ; 129.6\left(\mathrm{C}_{\text {arom }, 3^{\circ}}\right.$ ortho to $\left.\mathrm{SO}_{2}, 4 \mathrm{C}\right) ; 117.6\left(\mathrm{C}_{\text {arom }, 3^{\circ}}\right.$ meta to $\left.\mathrm{SO}_{2}, 4 \mathrm{C}\right)$; $111.7\left(\mathrm{C}_{\text {arom, } 3^{\circ}}\right.$ ortho to $\mathrm{O}$ para to $\left.\mathrm{NH}_{2}\right) ; 109.6$ $\left(\mathrm{C}_{\text {arom }, 3^{\circ}}\right.$ ortho to $\mathrm{NH}_{2}$, para to $\left.\mathrm{O}, 2 \mathrm{C}\right) ; 106.6\left(\mathrm{C}_{\text {arom }, 3^{\circ}}\right.$ meta to $\mathrm{NH}_{2}$ and $\left.\mathrm{O}, 2 \mathrm{C}\right)$. IR $(\mathrm{KBr}): 3483,3379$ $\mathrm{cm}^{-1}\left(\mathrm{~s}, \mathrm{NH}_{2}\right), 1151,1167 \mathrm{~cm}^{-1}(\mathrm{~S}=\mathrm{O}), 1236 \mathrm{~cm}^{-1}$ (phenyl ether). Anal. Calcd for $\mathrm{C}_{24} \mathrm{H}_{20} \mathrm{O}_{4} \mathrm{SN}_{2}$ (432.502): C, 66.65\%; H, 4.65\%; N, 6.59\%. Found: $\mathrm{C}, 66.66 \% ; \mathrm{H}, 4.67 \% ; \mathrm{N}, 6.58 \%$.

The synthesis of DAPDS/6FDA-based polyimide is shown in Scheme 1. In the first stage of the synthesis, $10.00 \mathrm{~g}(0.0231 \mathrm{~mol})$ of DAPDS was dissolved in $45.00 \mathrm{~g}$ of dry NMP in a $250 \mathrm{~mL}$ threenecked, round bottom flask equipped with a mechanical stirrer, a nitrogen inlet fitted with a thermocouple, and a condenser fitted with an inverse Dean-Stark trap. After complete dissolution of the diamine, $10.27 \mathrm{~g}(0.0231 \mathrm{~mol})$ of $6 \mathrm{FDA}$ was added to the stirring solution incrementally allowing the previously added portion of dianhydride to be dissolved before a new portion was added. After the addition of dianhydride was completed, the reaction was allowed to proceed for an additional $16 \mathrm{~h}$ at $25^{\circ} \mathrm{C}$ under nitrogen atmosphere. The solution thus prepared contained $20 \%$ $(\mathrm{w} / \mathrm{w})$ solids. In the second stage, $15.00 \mathrm{~g}$ of azeotropic agent was added to the flask and the solution was agitated with a mechanical stirrer and heated to $180^{\circ} \mathrm{C}$ under nitrogen purge. The progress of imidization was observed by the collection of water in the Dean-Stark traps. Polyimide was precipitated from methanol, rinsed with methanol, dried at $180^{\circ} \mathrm{C}$, and characterized.

\section{Preparation of PI/PPy Composite}

The electrochemical polymerization of pyrrole was carried out in a three-compartment cell with a $\mathrm{Pt}\left(1.5 \mathrm{~cm}^{2}\right)$ working electrode, a $\mathrm{Ag} / \mathrm{Ag}^{+}$reference electrode, and a Pt foil $\left(1.5 \mathrm{~cm}^{2}\right)$ counter electrode. The preparation of composites was done in an acetonitrile solution containing $0.03 \mathrm{~mol} / \mathrm{L} \mathrm{Py}$ and $0.04 \mathrm{~mol} / \mathrm{L}$ TBAFB. The solutions were purged with $\mathrm{N}_{2}$ before polymerizations for 10-15 min, and a blanket of $\mathrm{N}_{2}$ was used during the 


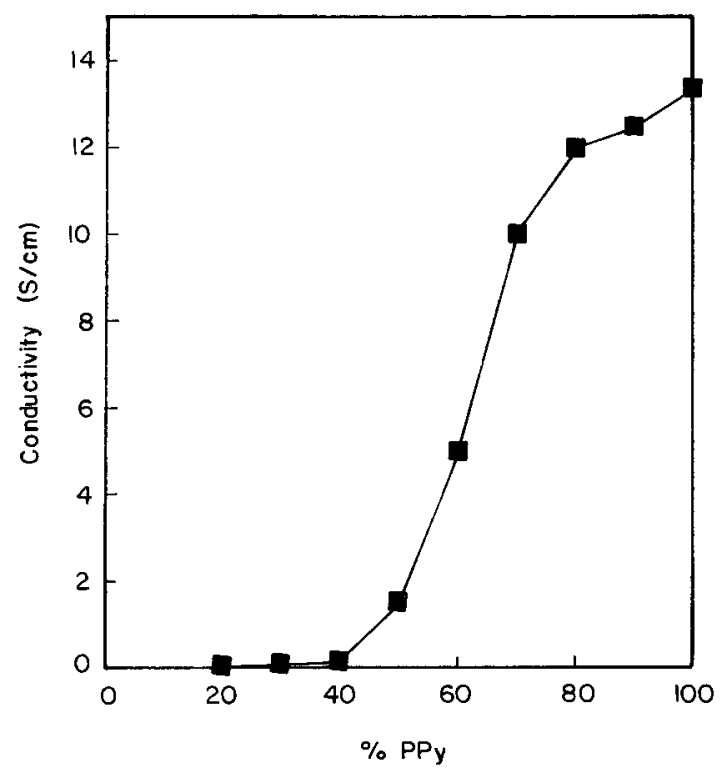

Figure 1. Conductivity vs. percent composition of $\mathrm{PPy}$.

experiments. In all cases, polymerizations were conducted at ambient temperature.

A polyimide-coated electrode (PI/Pt) was prepared by depositing a $1 \mathrm{wt} \%$ solution of PI in $\mathrm{CHCl}_{3}$ onto a $\mathrm{Pt}$ foil and allowing the solvent to evaporate completely. Thin films of dried polymer on Pt electrode were directly used for electrochemical polymerization. The electrochemical polymerization process was carried out potentiostatically at a constant voltage of $1.2 \mathrm{~V} \mathrm{vs.} \mathrm{Ag} / \mathrm{Ag}^{+}$to speed up the pyrrole polymerizations and overcome the resistance caused by the insulating film on the anode. After a suitable polymerization period (depending on the desired composition of polypyrrole) the films were removed with a doctor's blade. The films were washed with water and acetonitrile in order to remove the electrolyte and dried under vacuum.

As a control experiment, we repeated the above experiment with no pyrrole monomer in the cell. In this case we observed that the insulating polymer, PI, does not undergo oxidation under the conditions of the polymerization of pyrrole. In addition to this, the FTIR spectrum of the insulating polymer was taken before and after the electrolyses to rule out such a possibility.

\section{Characterization}

\section{Determination of Degree of Imidization by Potentiometric Titration}

Potentiometric titration techniques were used ${ }^{12}$ to determine the degree of imidization. A Met- rohm 655 Dosimat-614 Impulsomat automatic potentiometric titration assembly was used for titrations of carboxylic acid groups of poly (amic acid) solutions. For determinations, a $0.025 \mathrm{~N}$ methanolic solution of tetramethylammonium hydroxide which was standardized with potassium hydrogen phthalate was used.

\section{Fourier Transform Infrared Spectroscopy (FTIR)}

A Nicolet 510-P FTIR instrument was used to obtain spectra from $(\mathrm{KBr})$ pellets of polyimide and PI/PPy composites. All spectra were collected in 32 scans at a resolution of $4 \mathrm{~cm}^{-1}$.

\section{Nuclear Magnetic Resonance Spectroscopy (NMR)}

NMR spectroscopy techniques were used to characterize DCDS and DAPDS that were synthesized. A Brucker AC $200 \mathrm{~L}$ spectrometer operating at $200.132 \mathrm{MHz}$ for ${ }^{1} \mathrm{H}$ and $50.288 \mathrm{MHz}$ for ${ }^{13} \mathrm{C}$ was used to obtain the spectra.

${ }^{1} \mathrm{H}$ and ${ }^{13} \mathrm{C}$-APT spectra was recorded by dissolving DAPDS in deuterated chloroform $\left(\mathrm{CDCl}_{3}\right)$ using tetramethylsilane as the internal reference.

\section{Thermal Characterization}

Thermal characterization of the polyimide and the PI/PPy composites was carried out using a DuPont 990 modular thermal analyzer system, in conjunction with a 951 thermogravimetric analyzer and 910 differential scanning calorimeter. TG experiments were carried out under dry nitrogen purge at a rate of $30 \mathrm{~cm}^{3} \mathrm{~min}^{-1}$. A constant heating rate of $10^{\circ} \mathrm{C} \min ^{-1}$ was used.

\section{Elemental Analysis}

Elemental analyses of synthesized monomer were obtained by a Carlo-Erba 1106 elemental analyzer.

\section{Electrochemical Polymerization}

The electrochemical preparation of PI/PPy composites was accomplished with a Wenking POS 73 potentiostat.

\section{Scanning Electron Micrograph}

SEM was performed using a Jeol JSM 6400 scanning electron microscope. Despite their intrinsically conducting nature, all specimens were coated with gold prior to examination. 


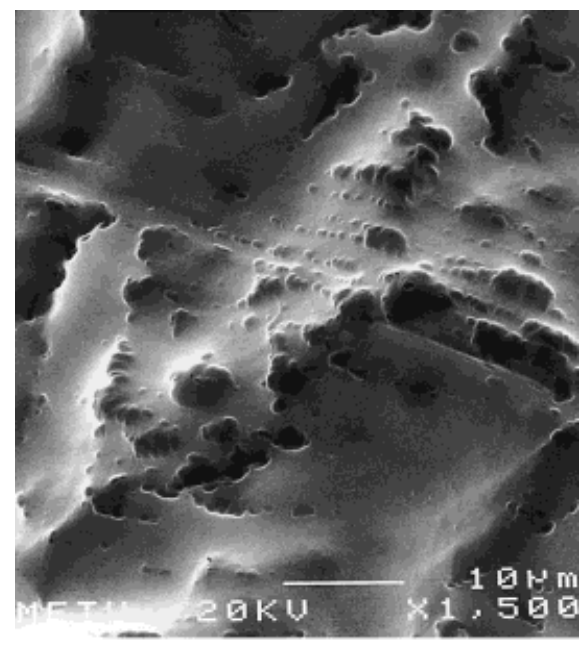

(a)

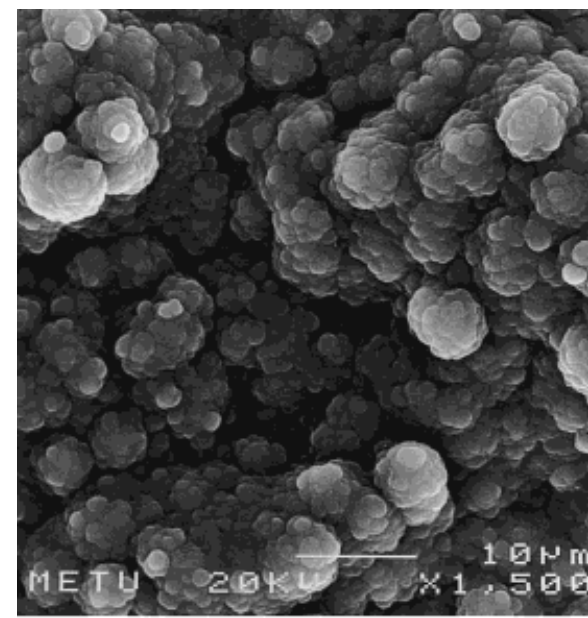

(c)

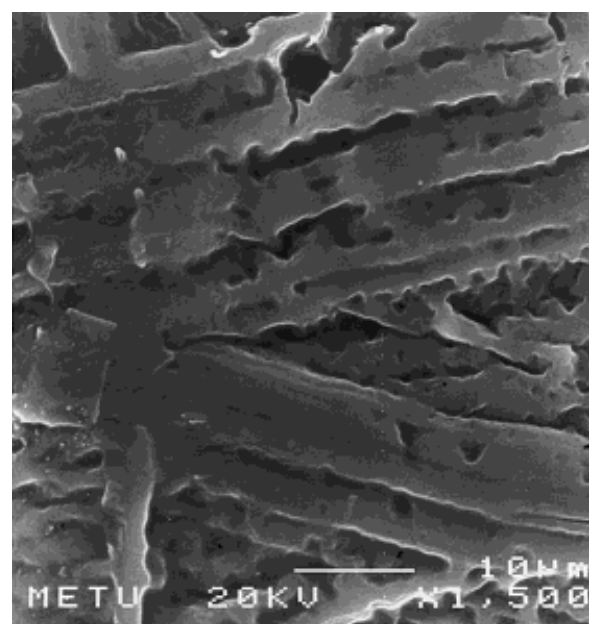

(b)

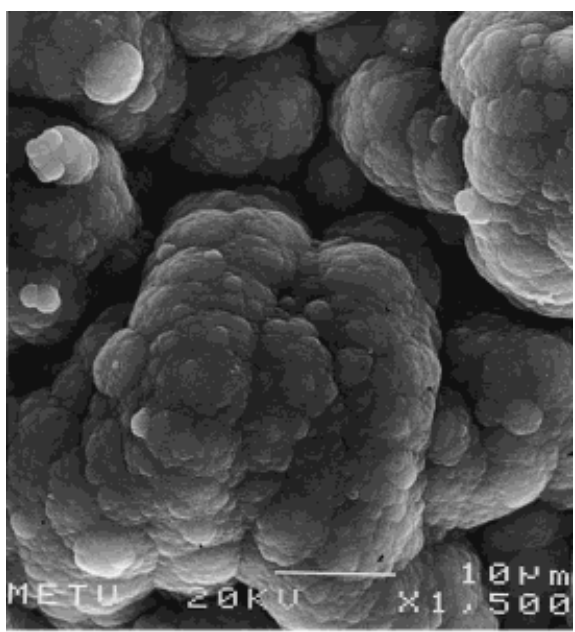

(d)

Figure 2. Scanning electron micrographs of (a) electrode side of pure PPy, (b) electrode side of PI/PPy film, (c) solution side of PI/PPy film, and (d) solution side of washed film.

\section{Cyclic Voltammetry Experiments}

Cyclic voltammetry experiments of PPy and PI/ PPy were carried out with HEKA potentiostat/ galvanostat. Dry acetonitrile solutions containing $0.1 M$ TBAFB and $10^{-3} M$ monomer were employed along with a Pt wire working and counter electrodes and a $\mathrm{Ag} / \mathrm{Ag}^{+}$reference electrode. Prior to all measurements, solutions were purged with $\mathrm{N}_{2}$ and during $\mathrm{CV}$ runs an $\mathrm{N}_{2}$ blanket was maintained over the solution.

\section{RESULTS AND DISCUSSION}

Since pyrrole was electrochemically polymerized onto a PI/Pt electrode, the transparent PI film coated on Pt turned light green and gradually darkened, finally becoming black.

The washing procedure with the solvent of PI was repeated for several weeks in order to see whether there was a change in weight or not. No marked changes were observed in conductivity and in the percent composition of PI in the composite.

\section{Conductivity of PI/PPy Composite Films}

The conductivity of the composite PI/PPy film was observed to increase as the electrochemical polymerization process of pyrrole continued at a constant potential of $+1.2 \mathrm{~V}$ in an acetonitrile/TBAFB 

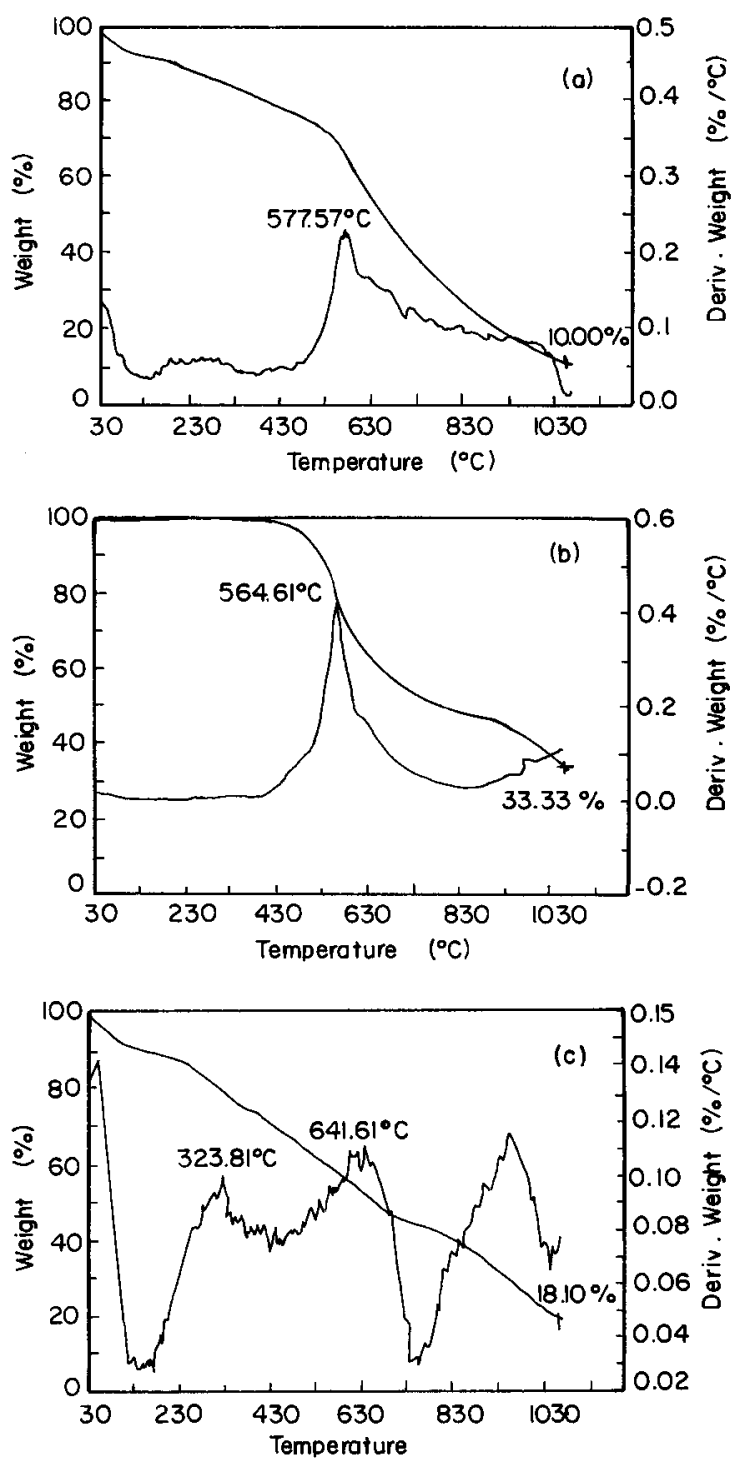

Figure 3. Thermal gravimetric analyses of (a) PI/ PPy composite film, (b) pure PI, and (c) pure PPy.

solution. After the PI film coated on the Pt electrode is sufficiently swollen by an electrolyte solution, pyrrole and electrolyte penetrate through the PI layer onto the Pt electrode surface. As a result, the pyrrole is electro-oxidatively polymerized on the Pt surface and doped by the counteranion at the same time. Reactants penetrating through the PI layer afterward will electrodeposit onto the surface of the PPy layer that has formed in the PI matrix. Having grown throughout the inside of the PI substrate, PPy grows out of the PI outer surface and makes that surface conducting. The weight percentage of PPy in the composites was determined gravimetrically. The PI-coated Pt foil electrodes were weighed before and after electrolysis. In Figure 1 the electrical conductivity, $\sigma$, is plotted as a function of PPy content of the composite film. From the conductivity measurements it was found that the conductivity of the film surface that was not in contact with Pt was about the same order of magnitude compared to that of the electrode side. It was found that the conductivity is proportional to the weight percentage and independent of the original thickness of the PI films as long as the PPy content is fixed. A homogeneous distribution of PPy in the matrix PI would lead to a sudden increase in conductivity. Therefore, we conclude that the initial deposition of PPy mainly occurs at the PI and the metal electrode interface and then reaches the surface of the insulating film.

\section{Morphology of Composites}

Figure 2 shows scanning electron micrographs (SEM) for PI/PPy composite films. A composite PI/PPy film's solution side (facing the electrolyte) has many cauliflower-like projections bulging
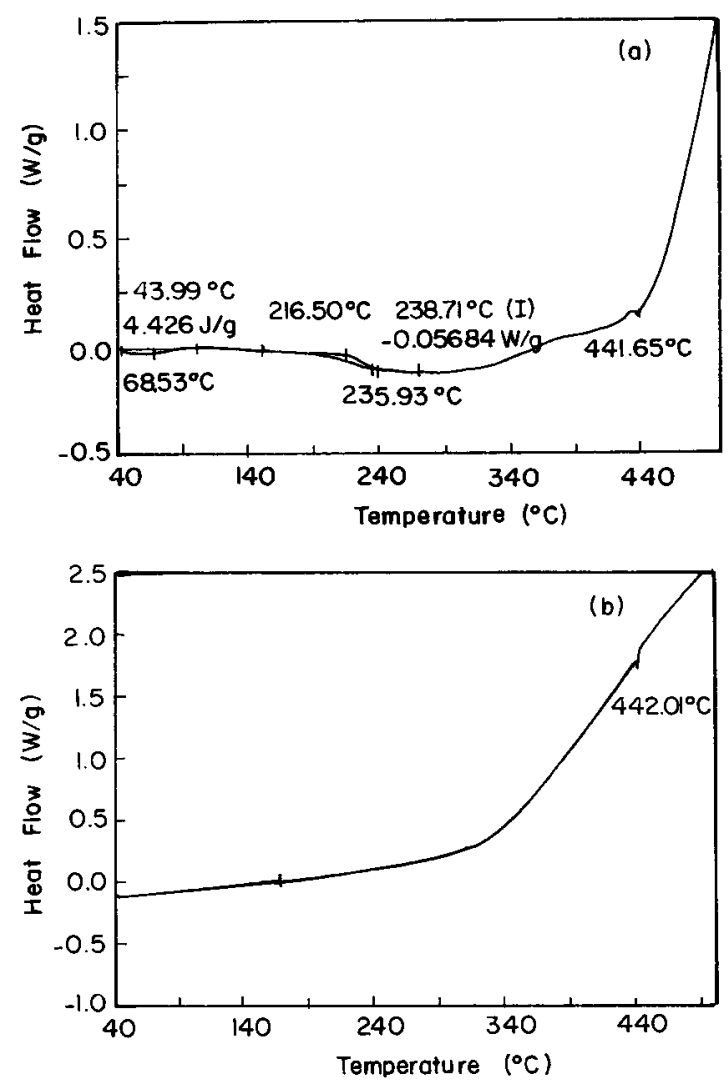

Figure 4. Differential scanning calorimetry of (a) pure PI and (b) electrolytic film. 
from the network of PI. No obvious difference could be detected between the micrographs of electrolytic film and that of the film washed with the solvent of polyimide. The electrode sides of both films also have the same appearance which may be an indication of a chemical interaction between the two polymers (Figure 2a,b).

\section{Thermal Analysis}

In thermogravimetric studies of the PPy/PI composites it was seen that the TG curve of the composite is not a simple addition of the pure polymers. The TG curves of pure polymers and composite film are given in Figure 3. 6FDA/DAPDSbased PI shows $10 \%$ wt loss at $564^{\circ} \mathrm{C}$. In comparison to the pure PI, the composite, PI/PPy, loses weight gradually over the temperature range. More than $60 \%$ of its weight was retained when heated to a temperature of $577^{\circ} \mathrm{C}$. The composite shows a rather high thermal stability.

Figure 4 a reveals the glass transition temperature of the polyimide as $238^{\circ} \mathrm{C}$. On the other hand, the electrolytic film has no features as to any thermal transition (Figure 4b). It seems that the behavior of the new material is quite different from that of either polypyrrole or polyimide.

\section{FTIR Analysis}

During cyclization FTIR characteristic peaks for polyamic acid, $1660 \mathrm{~cm}^{-1}$ (amide $\mathrm{I}, \mathrm{C}=\mathrm{O}$ stretching), $1550 \mathrm{~cm}^{-1}$ (amide II, CNH vibration), and $3240-3320 \mathrm{~cm}^{-1}(\mathrm{~N}-\mathrm{H}$ stretching $)$, were decreased and characteristic peaks for polyimide, $1780 \mathrm{~cm}^{-1}$ (symmetric $\mathrm{C}=\mathrm{O}$ stretching), 725 $\mathrm{cm}^{-1} \quad(\mathrm{C}=\mathrm{O}$ bending $)$, and $1380 \mathrm{~cm}^{-1}(\mathrm{CN}$ stretching), were observed. Polyimide displays two stretching bands in the carbonyl region. These characteristic peaks are present in the spectrum of composite film. The FTIR spectrum of composite show additional bands at 1161, 1416, 1463 , and $1551 \mathrm{~cm}^{-1}$ due to $\mathrm{C}-\mathrm{N}$ and $\mathrm{C}-\mathrm{C}$ stretchings in addition to an $\mathrm{N}-\mathrm{H}$ wagging band between 909 and $666 \mathrm{~cm}^{-1}$. These are the characteristic peaks of PPy. In the composite there is a slight shift in the characteristic absorption bands of PI. We washed the composite film with $\mathrm{CHCl}_{3}$ in order to remove unbounded PI from the composite. When we compare this with pure PPy and PI, it still shows characteristic absorption peaks of PI and some obvious differences from the pure PPy spectrum.

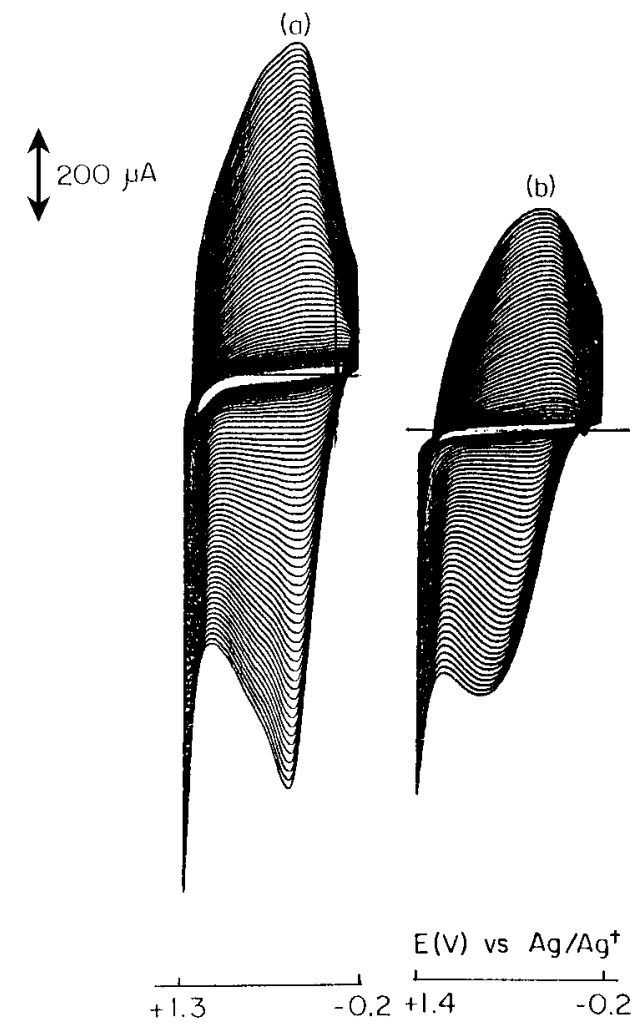

Figure 5. Multisweep cyclic voltammograms of pyrrole (a) on bare Pt electrode and (b) on PI-coated Pt electrode.

\section{Electroactivity of PPy and PI/PPy Composite Film}

The anion doping-undoping process for the PI/ PPy films was examined by the usual electrochemical techniques. Cyclic voltammetry experiments were performed with a potential scan from -0.2 to $+1.3 \mathrm{~V}$ on bare $\mathrm{Pt}$ and -0.2 to $+1.4 \mathrm{~V}$ on a PI-coated electrode versus $\mathrm{Ag} / \mathrm{Ag}^{+}$. The two cyclic voltammograms with $\mathrm{PI} / \mathrm{Pt}$ and $\mathrm{Pt}$ as the working electrode are compared in Figure 5. At the $\mathrm{Pt}$ electrode, pyrrole starts to polymerize at $+0.35 \mathrm{~V}$. The corresponding reduction peak is at around $+0.2 \mathrm{~V}$. The anodic peak potential of the polymer shifted slightly toward the anodic direction with repeated cyclings. The anodic peak potential which is at $+0.35 \mathrm{~V}$ at the first run shifts to $+0.45 \mathrm{~V}$. A multisweep cyclic voltammogram of the composite electrode is given in Figure 5b. It has an oxidation peak at around $+0.4 \mathrm{~V}$ and the corresponding cathodic peak at $+0.2 \mathrm{~V}$. There is a shift during cycling resembling a PPy cyclic voltammogram. The cathodic peak potential shifts to $+0.35 \mathrm{~V}$, and that of the anode, to $+0.8 \mathrm{~V}$. These differences result from the fact that before electro- 
polymerizing at the $\mathrm{PI} / \mathrm{Pt}$ electrode, $\mathrm{Py}$ and electrolyte have to diffuse onto Pt surface through a PI layer after having diffused to the PI layer's outer surface from the electrolyte solution. Repeated scanning over the potential range -0.2 to $+1.4 \mathrm{~V}$ results in small changes in the size of cyclic voltammetric redox peaks, indicating the electrochemical switching capacity of the PPy/PI composite film.

\section{CONCLUSION}

In this study, with the help of solubility tests together with thermal analyses, we believe that the composite film contains copolymers of PI and PPy to a certain extent. PI/PPy composite films show high electrical conductivity and electroactivity associated with stability to ambient conditions. Electrochemically synthesized thin films of PPy and PI/PPy show similar electroactivities. The conductivity of PPy is combined with the good thermal stability of PI, and this improvement may find several applications.

This work is partially supported by TBAG Grant 1422 . L.T. acknowledges TUBA support.

\section{REFERENCES AND NOTES}

1. N. V. Bhat and S. Yasmin, J. Appl. Polym. Sci., 55, 1827 (1995).

2. R. C. D. Peres and M. A. DePaoli, J. Pow. Sour., 40, 229 (1992).
3. M. R. Anderson, B. R. Mattes, H. Reiss, and R. B. Kaner, Science, 252, 1412 (1991).

4. A. Kaynak, J. Unsworth, G. E. Beard, and R. Clout, Mater. Res. Bull., 28, 1109 (1993).

5. G. A. Sotzing, J. R. Reynolds, and P. J. Steel, Chem. Mat., 8, 882 (1996).

6. F. Selampinar, U. Akbulut, T. Yalcin, S. Süzer, and L. Toppare, Synth. Met., 62, 201 (1994).

7. M. Makata and H. Kise, Polym. J., 25, 91 (1993).

8. A. Pron, M. Zagorska, W. Fabranowski, J. B. Raynor, and S. Lefrant, Polym. Commun., 28, 193 (1987).

9. J. Yang, Y. Yang, J. Hou, X. Zhang, W. Zhu, and M. Xu, Polymer, 37, 793 (1996).

10. H. L. Wang, L. Toppare, and J. E. Fernandez, Macromolecules, 23, 1053 (1990).

11. S. R. Sandler, Polymer Syntheses, Academic Press, New York, 1974.

12. Y. J. Kim, T. E. Glass, G. D. Lyle, and J. E. McGrath, Macromolecules, 26, 1344 (1993).

13. D. Wilson, H. D. Stezenberger, and P. M. Herginrother, Polyimides, Chapman \& Hall, New York, 1990.

14. C. E. Sroog, J. Poly. Sci. Macrom. Rev., 162, 1976.

15. K. Otmer, Encyclopedia of Chemical Technology, John Wiley \& Sons, New York, 1982.

16. R. L. Kaas, J. Polym. Sci., Polym. Chem., 19, 2255 (1981).

17. D. A. Lewis, J. D. Summer, T. C. Ward, and J. E. McGrath, J. Polym. Sci. Polym. Chem., 30, 1467 (1992).

18. C. Ferger, M. M. Khojasteh, and J. E. McGrath, Polyimides, Materials, Chemistry and Characterization, Elsevier, Amsterdam, 1989.

19. T. Yilmaz, MS Thesis, Istanbul Technical University, 1993.

20. Chem. Abstr., 112, 180399 (1990).

21. Snell-Ettre, Encyclopedia of Industrial Chemical Analysis, John Wiley \& Sons, New York, 1971. 